\title{
Crime and Disruption in North Carolina Libraries
}

\author{
Alan Jay Lincoln
}

The United States has one of the highest crime rates of any industrialized nation. We experience high levels of crime in the private sector (between friends, acquaintances, and family members), and we also experience high levels of crime in the public sector (against commercial establishments, in schools, parks, etc.). In addition, our crime rates have been increasing in recent years. It is likely that public libraries are no longer immune from these crime patterns. In fact, libraries probably reflect much of the crime found in the surrounding community.

The types of crime that affect libraries vary. Book theft is a significant and costly problem. Many libraries have had problems with the mutilation of books and periodicals $(4,8)$. Sometimes these acts are done for profit, but other times for the convenience of the patron. Vandalism is one of the more common types of disruptive behaviors. Episodes range from ice cream in the book drops, to spray painting walls, to full scale destruction of windows, equipment, and materials $(2,8,9)$. Arson and attempted arson are not unknown and can have a devastating effect on the physical property as well as the budget $(1,9)$.

In addition to crimes directed against property there may be other acts focused against persons. Once again, the severity of the episodes varies. At one extreme we know of many cases of verbal abuse $(5,6)$. However, the problems can include assault and robbery both inside the library and on the surrounding walkways and parking lots $(6,7)$.

The actual occurrence or the fear of crime can have long-lasting effects on the behavior of both staff and patrons. When studying the effects of crime we should consider two types of costs, direct and indirect. Direct costs are those

\footnotetext{
Alan Jay Lincoln is associate professor of law and justice and director, Center for Study of Crime in Public Places, University of Lowell, Mass. This study is one of a series of state level studies of crime and disruption in public libraries. A listing of related reprints is available upon request from the author. Please enclose a self-addressed, stamped envelope.
}

that are the actual result of the specific offense. For example, this would include the actual losses, replacement costs, and the costs of any injuries.

Just as important to examine, but more difficult to assess are the indirect costs. They may in reality have greater impact on the institution and be more widespread. For the individual staff member or patron the indirect costs may be more traumatic and long lasting than direct costs. Indirect costs are the reactions to crime. That is, reactions to past or anticipated crime. Increased or new security measures are indirect costs. Changing or limiting open hours because of crime patterns are indirect costs. Any behavior changes made by staff or patron due to crime can be considered indirect costs-including not using the library.

Our series of state studies on crime and disruption are designed to obtain information not only on the patterns of crime that occur in libraries but also on the costs involved. Hopefully, identifying these previously little known patterns will aid in prevention and elimination of the problems.

\section{Procedure}

Sample. North Carolina was one of thirteen states selected for study in the current series of surveys. A systematic sample of sixty public libraries were drawn for each state. From the comprehensive listing of all public libraries in the American Library Directory, every " $n$ th" library was selected. The ratio was determined by dividing the total number of public libraries by sixty. For example, if a state had 120 public libraries, then every second library in the listing was included in the sample. In this way a representative sample for each state was obtained.

Materials. An explanatory cover letter, the survey instrument, and a non-stamped return envelope were sent to the head librarian in each of the sampled libraries during October, 1981. The survey instrument was comprised of a four page, 68 item questionnaire. The items were 
developed following a review of current literature related to both library science and criminal victimization of other public institutions. Questions covered topics including: (1) characteristics of the library, (2) characteristics of the community, (3) patron use patterns, (4) experiences with 18 different types of crimes, (5) direct and indirect costs of crime, (6) use of security equipment and procedures, and so on. All items were fixed alternative questions constructed to obtain "computer ready" responses. The survey was designed so that the identity of the library would not be known unless the respondent chose to reveal it. Returned surveys were coded and the data keypunched in preparation for analysis.

\section{Results}

The systematic sampling of 60 North Carolina libraries resulted in a return of 29 questionnaires to date. This is an average return for mailed victimization surveys of this type. All of the data analyses were conducted using the Statistical Package for the Social Sciences. In this report we will present data describing the frequency of 18 different types of crime and disruption. In addition, summary indices were computed and these data will be presented.

The findings related to patterns of victimization are presented in Table 1 . The crimes described fall into six general categories: (1) vandalism/damage, comprised of items A,F, G,H,I,J; (2) theft, items B,C,D,E; (3) drug offenses, $\mathrm{K}$ and $\mathrm{L}$; (4) indecent exposure, $\mathrm{O}$; (5) arson, R; and (6) assault, P and Q. Two items (M and $\mathrm{N}$ ) asked about verbal abuse of the staff and patrons.

Table 1 describes how often (using five categories of frequencies) each of the acts occurred in the previous 12 months in our sample of North Carolina libraries. The following description of the findings will be limited to the percentage of libraries reporting at least one episode of each act, six or more occurrences of each act, and the summary index for the type of offense. We consider six or more repetitions of the same act to be a chronic problem deserving special attention.

The most common type of vandalasim/ damage was intentional book damage. Seventyone per cent of responding librarians were aware of at least one such episode, while $30 \%$ had six or more occurrences. Vandalism outside the building was reported in $54 \%$ of the cases. Inside vandalism was found in over $60 \%$ of the libraries but was chronic in only $15 \%$. Vandalism of cars belonging to the staff and patrons occurred less often than building vandalism. However, approximately onefourth of the libraries were aware of a patron's

TABLE 1

Percentage of Public Libraries Reporting Disruptive Episodes For A Twelve Month Period.

\begin{tabular}{|c|c|c|c|c|c|}
\hline \multirow[b]{2}{*}{ TYPE OF EPISODE } & \multirow[b]{2}{*}{0} & \multicolumn{3}{|c|}{ NUMBER OF EPISODES } & \multirow[b]{2}{*}{ CVEE 10} \\
\hline & & 1.2 & 3.5 & $6 \cdot 10$ & \\
\hline A. Intentional Book Damage & 29 & 21 & 21 & 13 & 17 \\
\hline B. Book Theft & 12 & 08 & 08 & 16 & 56 \\
\hline C. Reference Material Stolen & 31 & 23 & 19 & 12 & 15 \\
\hline D. Equipment Stolen & 67 & 26 & 04 & 00 & 04 \\
\hline E. Other Theft & 70 & 20 & 05 & 05 & 00 \\
\hline F. Vandalism Outside Building & 46 & 29 & 18 & 07 & 00 \\
\hline G. Vandalism Inside Building & 37 & 33 & 15 & 15 & 00 \\
\hline H. Vandalism of Patron's Car & 73 & 15 & 08 & 04 & 00 \\
\hline I. Vandalism of Staff Car & 68 & 16 & 08 & 04 & 04 \\
\hline J. Vandalism of Equipment & 80 & 12 & 08 & 00 & 00 \\
\hline K. Drug Use By Staff/Patron & 62 & 23 & 08 & 04 & 00 \\
\hline L. Drug Sale By Staff/Patron & 100 & 00 & 00 & 00 & 00 \\
\hline M. Verbal Abuse To Patron & 70 & 15 & 07 & 04 & 04 \\
\hline N. Verbal Abuse To Staff & 52 & 22 & 19 & 04 & 04 \\
\hline O. Indecent Exposure & 74 & 15 & 07 & 04 & 00 \\
\hline P. Assault On Patron & 93 & 04 & 04 & 00 & 00 \\
\hline Q. Assault On Staff & 96 & 00 & 04 & 00 & 00 \\
\hline R. Arson & 93 & 07 & 00 & 00 & 00 \\
\hline
\end{tabular}


car being vandalized while nearly a third reported vandalism to a staff car. The summary index of vandalism that includes all of the related items shows that $82 \%$ of responding libraries reported at least one act of some kind of vandalism.

Examination of the items related to theft show that book theft was the most frequent and consistent problem that we measured. Over $85 \%$ of the returns indicated at least one episode, and $72 \%$ reported over six episodes. The theft of reference material occurred in $69 \%$ of the libraries and was a chronic problem in $27 \%$. Other thefts were reported by nearly a third of our sample. Theft of equipment was also found in one-third of our responses. The theft index shows that $3 / 4$ of the responding libraries reported at least one theft.

The use and sale of drugs in the library was less common than either theft or vandalism. Nearly $40 \%$ were aware of drug use by the staff or patrons. However, there were no reports of drug sales. Indecent exposure was reported by $26 \%$ of the respondents, but was rarely chronic. Episodes of exposure (and other types of crimes) are not always brought to the attention of the staff. We suspect that many of our estimates of crime are conservative. Many episodes go undetected and some known episodes may not be reported to us.

Verbal abuse to the staff was reported to be a problem in nearly a half of the libraries. In contrast, verbal abuse of a patron was noticed in only $30 \%$ of the cases. We also computed a total index which describes how often any of the types of crime and disruption occurred. Only $13 \%$ of the libraries responding to our survey were free of all acts that we asked about.

Compared with the other twelve states in this portion of the library crime project, the participating North Carolina libraries experienced average amounts of theft, verbal abuse, and assault. The rates of drug problems and vandalism were higher than average. The overall measure of crime and disruption was slightly higher than the average found for the full sampling of states. These state level comparisons must be viewed cautiously since these data have not been controlled for factors that affect the crime rate. Crime rates are influenced not only by the state of location, but also by factors such as city size, use of security, and the characteristics of the community and neighborhood in which the library is located.

Identification of the patterns of crime and disruption can be the first step in developing programs to minimize the problems. These programs can be implemented in many cases with the support of the staff and public and at low cost to the institution.

\section{References}

1. "Fire and flood bulletin: New England libraries hit." Library Journal, (January 15, 1976): 299.

2. "Frightening events at NYPL and Boston Public." Wilson Library Bulletin, 52, (1977): 217.

3. Gjettum, P., "Burglars, burglars." American Libraries, 9. (1979): 233-34.

4. Hendrick, C., and Murfin, M., "Project library rip-off: A study of periodical mutilation in a university library." College and Research Libraries, (Nov., 1974): 402.

5. "In New York: Reading between the lions." Time (October 8, 1979): 18 .

6. Lincoln, A., and Lincoln, C., "The impact of crime in public libraries." Library and Archival Security, In press.

7. "Part-time attendants combat vandals." Library Association Record, 79 (1977): 244.

8. "Periodical mutilation zooms," Library Journal, 100, 12, (1975): 1172.

9. "Vandals blamed for large fire." Library Association Record, 80 , (1978): 52.

10. "Vandals cause damage, $\$ 100,000$." Publishers Weekly, 213, (1978): 26.

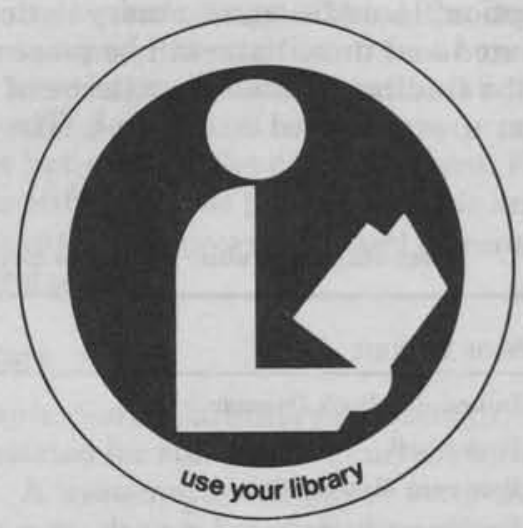

Continued from p. 79

\section{References}

1. For example: Marty Carroll. "Follow the Yellow Brick Road! A Potpourri of Ideas, Gimmicks, Suggestions, Plans, Tips, Themes, Contests, Notions, Hints, Advice, Tricks, Reminders, Et Cetera." Unabashed Librarian 36 (1980):14-15; Helen Carter. "Planning for Successful Special Events." Unabashed Librarian 36 (1980): 7.

2. John S. Robothan. Library Programs: How to Select, Plan and Produce Them. Metuchen, New Jersey; 1981.

3. Two of these include K. R. Haycock. "Program advocacy the missing element," Emergency Librarian 7 (March-June 1980): 3-5; M.S. Edsall. "Programming with a purpose." Library PR News vol. 2, no. 7-8 (July-August 1979): 1-3. 